\title{
Model Deteksi Krisis Indonesia dengan Indikator Suku Bunga Simpanan Riil
}

\author{
Rina Safitri ${ }^{1, *}$, Sugiyanto ${ }^{2}$, Sri Sulistijowati Handajani ${ }^{3}$ \\ 1,2,3Program Studi Statistika; Universitas Sebelas Maret; \\ e-mail: rinasafitri455@gmail.com, sugiyanto06@staff.uns.ac.id, $\underline{\text { ssulistijowati@yahoo.com }}$ \\ * Korespondensi: e-mail: rinasafitri455@gmail.com
}

\begin{abstract}
ARTICLE INFO
ABSTRACT

Keywords:

Crisis,

$M S-E C M$,

Interest rate

The financial crisis is a condition where a country's finances experience a disruption which is characterized by a drastic increase in the inflation rate, a weakening currency exchange rate, and a decrease in other economic activities. Indonesia experienced financial crises in 1997 and 1998 which resulted in a collapse of financial conditions and national stability. Therefore, it is necessary to have a model to find out the crisis, so that efforts to recover the impact of the crisis can be done as early as possible from the model. This study aims to apply the Markov Switching Error Correction Model to detect a crisis. Based on the indicator of real deposit interest rates it can be concluded that the MS-ECM can explain the crisis that occurred in mid1997 and late 2005
\end{abstract}

\section{PENDAHULUAN}

Krisis merupakan suatu bentuk gangguan stabilitas sistem keuangan dalam tatanan perekonomian. Untuk menjaga stabilitas tersebut harus dilakukan pemantauan dan identifikasi kemungkinan terjadi krisis, sehingga upaya pemulihan dan penyelesaian dampak dari krisis dapat dilakukan semaksimal mungkin, (Wahyudi, 2013). Krisis perbankan pada tahun 1997-1998 yang tidak terdeteksi secara dini akan mengakibatkan runtuhnya kepercayaan masyarskat terhadap industri perbankan.

Bank merupakan suatu lembaga yang bertugas menyalurkan dana dari pihak yang kelebihan dana kepada pihak yang membutuhkan dana. Kegiatan utama bank meliputi penyimpanan dan peminjaman uang. Tingkat bunga yang diberikan bank kepada nasabah atas simpanannya disebut suku bunga simpanan. Sedangkan tingkat bunga yang diberikan bank kepada nasabah atas pinjamannya disebut suku bunga pinjaman. Suku bunga simpanan riil merupakan suku bunga simpanan yang dikurangi dengan tingkat inflasi. Inflasi dapat mengurangi bunga simpanan yang diperoleh nasabah. Suku bunga riil menggambarkan keuntungan nasabah yang sudah tidak terpotong oleh inflasi.

Dwi (2001) melakukan analisis makro kinerja pasar modal Indonesia dengan pendekatan Error Correction Model (ECM). Pada tahun 2018, Sugiyanto et al melakukan penelitian tentang deteksi krisis keuangan dengan indikator output real, domestic credit per gross domestic product (GDP), dan IHSG menggunakan kombinasi model volatilitas dan Markov switching.

Indikator suku bunga simpanan riil merupakan data time series yang berfluktuatif, sehingga tidak stasioner yang berpotensi berkointegrasi. Kointegrasi artinya terdapat suatu hubungan jangka panjang antar indikator. Data yang berkointegrasi dapat dianalisa menggunakan Error Correction Model (ECM).

Data suku bunga simpanan riil mengalami perubahan kondisi (state) antara kondisi tidak krisis dan krisis sehingga harus digunakan model Markov switching. Hamilton (1994) memperkenalkan model Markov switching (MS) untuk memodelkan data runtun waktu yang mengalami perubahan kondisi. Dalam penelitian ini akan dibahas mengenai pendeteksian dini krisis keuangan di Indonesia berdasarkan indikator suku bunga simpanan riil menggunakan gabungan Error Correction Model dan Markov switching.

\section{METODE PENELITIAN}

Analisis runtun waktu pertama kali diperkenalkan dan dikembangkan pada tahun 1970 oleh Box dan Jenkins. Runtun waktu adalah himpunan observasi terurut dalam waktu. Analisis runtun waktu merupakan 
analisis sekumpulan data dalam suatu periode waktu lampau yang berguna untuk mengetahui atau meramalkan kondisi masa mendatang. Hal ini berdasarkan perilaku manusia yang banyak dipengaruhi oleh kondisi atau waktu sebelumnya sehingga faktor waktu sangat penting peranannya (Gujarati, 2003).

Data yang digunakan adalah data bulanan suku bunga simpanan riil (SBSR) dan selisih BI rate riil dengan FED rate riil (SBIRFER) dari Januari 1990 sampai Desember 2018 diambil dari International Financial Statistics (IFS). Data suku bunga simpanan riil merupakan data time series yang berfluktuasi, sehingga tidak stasioner. Error Correction Model (ECM) merupakan model yang digunakan untuk data tidak stasioner dan berkointegrasi. Dalam melihat kestasioneritasan dapat digunkaan uji Augmented Dickey Fuller (ADF). Menurut Tsay (2002), hipotesis dari uji ADF dapat dituliskan sebagai berikut:

$\mathrm{H}_{0}$ : data runtun waktu tidak stasioner

$\mathrm{H}_{1}$ : data runtun waktu stasioner

Apabila hasil uji ADF menunjukkan data tidak stasioner maka perlu dilakukan transformasi pada data. Rosadi (2010) memaparkan bahwa data yang tidak stasioner dapat diubah menjadi data stasioner dengan melakukan pembedaan. Pembedaan memiliki rumus sebagai berikut:

$$
\Delta Y_{t}=Y_{t}-Y_{t-1}
$$

dengan $\Delta \mathrm{Y}_{\mathrm{t}}$ adalah nilai pembedaan pada waktu ke- $t, Y_{t}$ adalah data observasi pada waktu ke- $t$ dan $Y_{t-1}$ adalah data observasi pada waktu ke-t-1. Estimasi persamaan ECM menurut Rosadi (2010) dapat ditulis sebagai berikut :

$$
\Delta \mathrm{Y}_{\mathrm{t}}=\beta_{0}+\beta_{1} \Delta \mathrm{X}_{\mathrm{t}}+\varphi \mathrm{Z}_{\mathrm{t}-1}+\mu_{\mathrm{t}}
$$

dengan $\Delta Y_{t}$ merupakan pembedaan $Y_{t}, \beta_{0}$ merupakan konstanta, $\Delta X_{t}$ merupakan pembedaan dari $X_{t}, Z_{t-1}$ merupakan error yang diperoleh dari persamaan regresi antara $Y_{t}$ dan $X_{t}$ pada lag ke-1 dan disebut juga ECT (Error Correction Term), $\mu_{t}$ merupakan residu, $\varphi$ merupakan koefisien kointegrasi. Menurut Muhammad (2014), uji kointegrasi dapat dilakukan dengan metode Engle-Granger. Pada metode ini dapat dikatakan terkointegrasi apabila residu regresi antara $Y_{t}$ dan $X_{t}$ stasioner. Secara umum model MS(M)-ECM memiliki rumus sebagai berikut:

$$
\Delta \mathrm{Y}_{\mathrm{t}}=\beta_{0, \mathrm{st}}+\beta_{1, \mathrm{st}} \Delta \mathrm{X}_{\mathrm{t}}+\varphi_{s t} \mathrm{Z}_{\mathrm{t}-1}+\mu_{\mathrm{t}}
$$

dengan $\Delta Y_{t}$ adalah mengikuti proses ECM, $\beta_{0, s t}$ adalah konstan, dan $s_{t}$ merupakan random tak teramati yag bernilai $1,2,3, \ldots, k$ dengan asumsi mengikuti proses rantai Markov orde pertama dengan probabiltas transisi diberikan oleh

dalam notasi matriks, $\mathrm{P}$ dapat didefinisikan oleh

$$
P\left[s_{t}=j \mid s_{t-1}=i\right]=p_{i j}, \sum_{j=1}^{T} p_{i j}=1 \text {, for } i, j=1,2, \ldots, T \text {. }
$$

$$
\mathrm{P}=\left(\begin{array}{cccc}
\mathrm{p}_{11} & \mathrm{p}_{21} & \ldots & \mathrm{p}_{\mathrm{T} 1} \\
\mathrm{p}_{12} & \mathrm{p}_{22} & \ldots & \mathrm{p}_{\mathrm{T} 2} \\
\vdots & \vdots & \ddots & \vdots \\
\mathrm{p}_{1 \mathrm{~T}} & \mathrm{p}_{2 \mathrm{~T}} & \ldots & \mathrm{p}_{\mathrm{TT}}
\end{array}\right) .
$$

\section{HASIL DAN PEMBAHASAN}

Pada bagian ini, dijelaskan plot data, uji stasioneritas, derajat kointegrasi, Error Correction Model, dan Markov Switching Error Correction Model

\subsection{Pola data}

Plot data suku bunga simpanan riil dan selisih BI rate riil dengan FED rate riil masing-masing dapat dilihat pada Gambar 1(a) dan Gambar 1(b). 


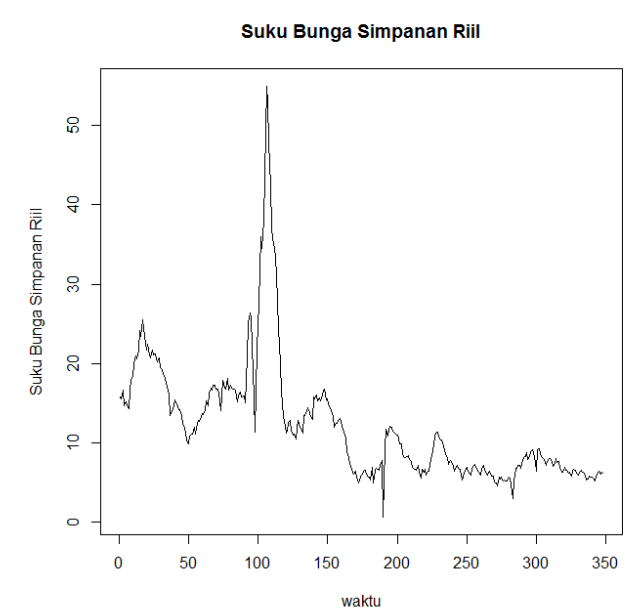

(a)

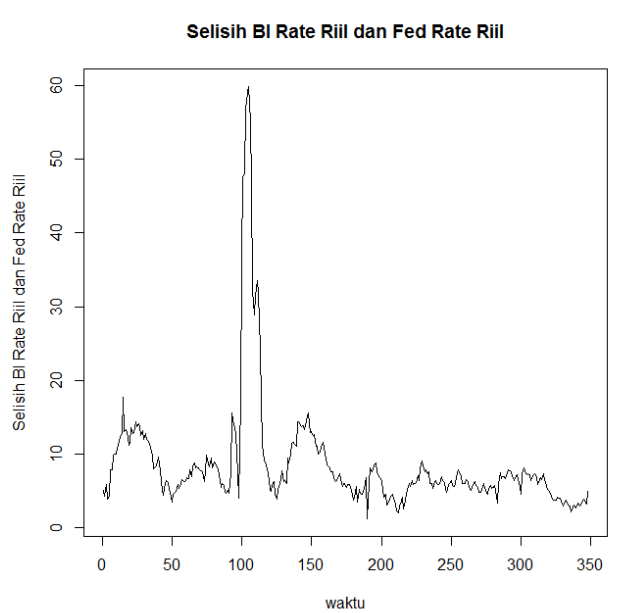

(b)

Gambar 1. Plot indikator (a) selisih BI rate riil dengan FED rate riil dan (b)suku bunga simpanan riil

Gambar 1(a) memuat trend yang mengindikasikan bahwa data tidak stasioner, namun Gambar 1(b) kurang terlihat memuat trend sehingga untuk lebih jelasnya dapat dilihat dari uji ADF.

\subsection{Uji Stasioneritas data dan Derajat Integrasi}

Tabel 1. Uji stasioneritas data

\begin{tabular}{|l|r|l|}
\hline \multirow{2}{*}{\multicolumn{1}{|c|}{ Variabel }} & \multicolumn{2}{c|}{ level } \\
\cline { 2 - 3 } & $\boldsymbol{A D F}$ & $\boldsymbol{p}$-value \\
\hline Selisih BI Rate Riil dan FED Rate Riil & -3.1558 & 0.0956 \\
\hline Suku Bunga Simpanan Riil & -2.6348 & 0.0870 \\
\hline
\end{tabular}

Berdasarkan uji ADF diperoleh nilai probabilitas lebih besar dari 0.05, yang berarti bahwa data tidak stasioner sehingga dapat dilakukan pendekatan Error Correction Model (ECM). Syarat uji kointegrasi yang harus dipenuhi adalah indikator mempunyai derajat integrasi yang sama. Derajat integrasi dapat dilihat dengan mentransformasikan data menggunakan pembedaan. Plot transformasi suku bunga simpanan riil dan selisih BI rate riil dengan FED rate riil masing-masing dapat dilihat pada Gambar 2(a) dan Gambar 2(b).

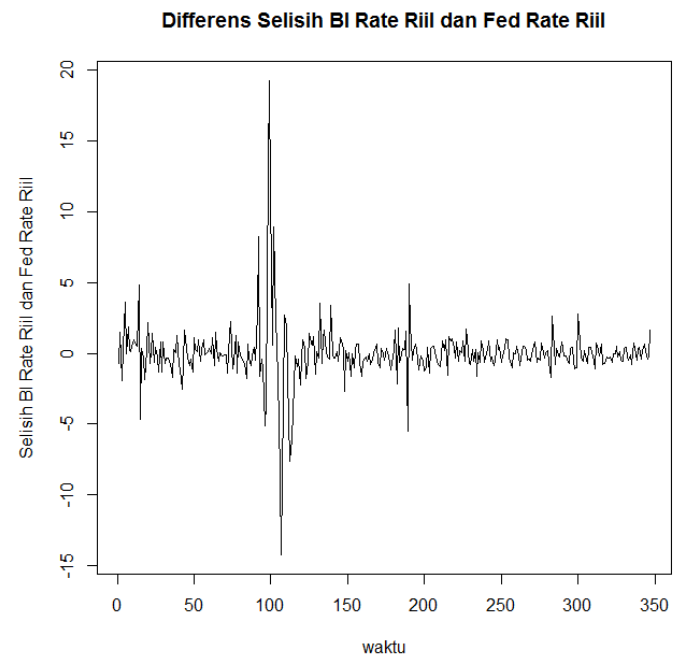

(a)

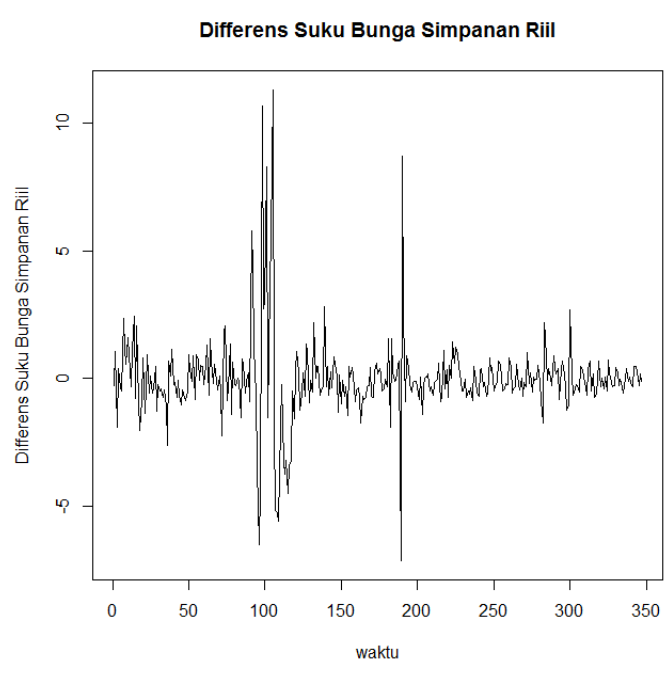

(b)

Sumber: Hasil Penelitian (2019)

Gambar 2. Plot pembedaan (a) selisih BI rate riil dengan FED rate riil dan (b) suku bunga simpanan riil.

Gambar 2(a) dan Gambar 2(b) menunjukkan bahwa data pembedaan tidak mengandung trend yang mengindikasikan bahwa data stasioner. Kestasioneran data dapat ditunjukkan oleh uji ADF. 
Tabel 2. Uji ADF Data Transformasi

\begin{tabular}{|l|c|c|}
\hline \multirow{2}{*}{ Variabel } & \multicolumn{2}{|c|}{$\mathbf{1}^{\text {st }}$ differences } \\
\cline { 2 - 3 } & ADF & p-value \\
\hline Selisih BI Rate Riil dan FED Rate Riil & -10.82912 & 0.000 \\
\hline Suku Bunga Simpanan Riil & -6.992768 & 0.000 \\
\hline
\end{tabular}

Sumber: Hasil Penelitian (2019)

Tabel 2. memperlihatkan bahwa data selisih BI rate riil dan FED rate riil dan suku bunga simpannan riil merupakan data yang tidak stasioner pada level. Sementara itu, dari hasil pembedaan pertama dapat dilihat bahwa $p$-value statistik ADF dari masing-masing variabel lebih kecil dari $\alpha=5 \%$, ini artinya menolak hipotesis $H_{0}$ yaitu data stasioner. Dengan demikian, data selisih BI rate riil dan FED rate riil dan suku bunga simpannan riil merupakan data stasioner pada tingkat pembedaan yang pertama.

\subsection{Uji Kointegrasi}

Uji kointegrasi dapat terpenuhi apabila residu dari regresi antara suku bunga simpanan riil dan selisih BI rate riil dengan FED rate riil stasioner. Hasilnya terlihat bahwa residu memiliki nilai p-value < 0.05 yang berarti bahwa kointegrasi terpenuhi, sehingga dapat dilanjutkan estimasi ECM.

\subsection{Error Correction Model (ECM)}

Tabel 4. Estimasi Error Correction Model

\begin{tabular}{|l|l|l|}
\hline \multicolumn{1}{|c|}{ Variabel } & \multicolumn{1}{c|}{ Koefisien } & p-value \\
\hline $\mathrm{D}($ SBIRFER) & 0.397 & 0.000 \\
\hline ECT(-1) & -0.107 & 0.000 \\
\hline
\end{tabular}

$\triangle \mathrm{SBSR}=0.387 \Delta \mathrm{SBIRFER}-0.107 \mathrm{ECT}(-1)$

Pada Tabel 5. dapat dilihat bahwa masing-masing koefisien dari variabel memiliki nilai $p$-value < 0.05. Hal ini menunjukkan bahwa semua koefisien signifikan.

\subsection{Markov Switching Error Correction Model (MS-ECM)}

Regime merupakan perubahan kondisi (state) yang terjadi dalam model Markov switching. Indikator sukubunga simpanan riil memiliki 2 regime. Regime 1 menggambarkan volatilitas rendah dan regime 2 menggambarkan volatilitas tinggi. Suatu regime mempunyai kemungkinan untuk bertahan pada regime yang sama atau pindah ke regime yang lain pada waktu berikutnya. Probabilitas dari perubahan regime dapat dilihat dalam bentuk matriks probabilitas transisi. Matriks probabilitas transisi 2 regime untuk suku bunga simpanan riil sebagai berikut

$$
P=\left(\begin{array}{cc}
0.98526904 & 0.01473096 \\
0.1087938 & 0.8912062
\end{array}\right)
$$

Berdasarkan matriks probabilitas transisi tersebut, dapat dilihat nilai probabilitas untuk bertahan pada volatilitas rendah sebesar 0.98526904 dan probabilitas untuk bertahan pada volatilitas tinggi sebesar 0.8912062

Pendeteksian krisis dapat dilihat dari nilai probabilitas smoothed paling rendah pada saat krisis terjadi di Indonesia Diperoleh hasil bahwa krisis terjadi ketika nilai probabilitias smoothed lebih dari 0.98. Plot nilai probabilitas smoothed suku bunga simpanan riil dapat dilihat pada Gambar 3.
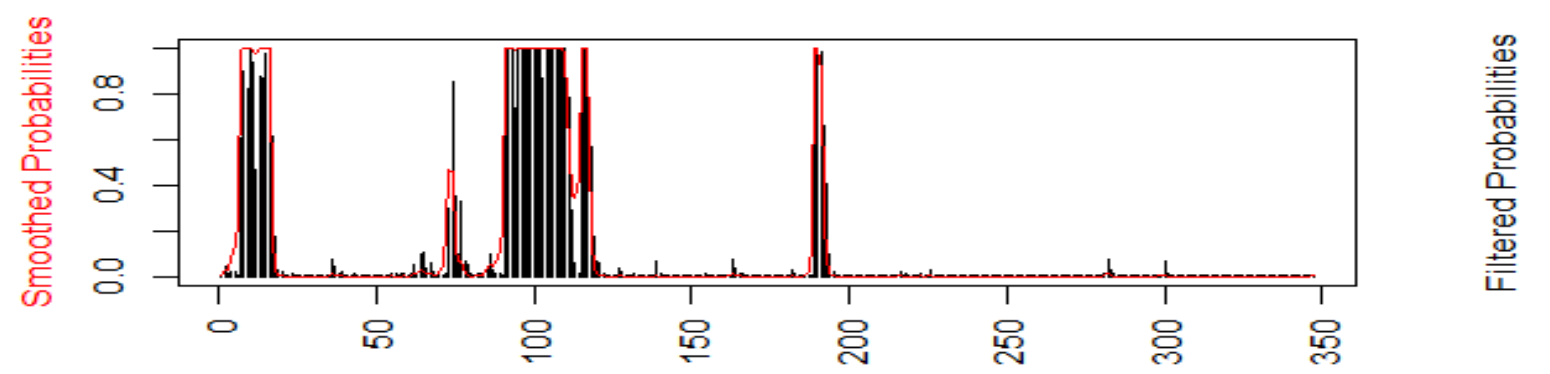

Gambar 3. Smoothed probability suku bunga simpanan riil

Gambar 3 menunjukkan terdapat 32 nilai probabilitas smoothed yang lebih besar dari 0.98. Krisis terdeteksi pada September 1990 - Desember 1990, Agustus 1997 - Februari 1999, Agustus 1999 -Oktober 1999, dan Oktober 2005 - November 2005. Dapat disimpulkan bahwa model MS-ECM dapat mendeteksi krisis indikator suku bunga simpanan riil. 


\section{KESIMPULAN}

Berdasarkan indikator suku bunga simpanan riil, model MS-ECM mampu mendeteksi krisis yang terjadi pada tahun 1997-1998 dan akhir tahun 2005.

\section{REFERENSI}

Dwi, R.A. 2001. Analisis Makro Kinerja Pasar Modal Indonesia dengan Pendekatan Error Correction Model (ECM). Jurnal Ekonomi Pembangunan Kajian Ekonomi Negara Berkembang Hal 13-32

Gujarati, D.N. 2003. Basic Econometrics 4th Edition. New York: McGrawHill.

Hamilton, J.D. 1989. A New Approach to the Economic Analysis of Nonstationary Time Series and the Business Cycle. Econometrica Vol. 57. No. 2. pp. 357-384.

Kim, C.J. and Nelson, C.R., State-Space Models with Regime Switching: Classical and Gibbs-Sampling Approaches with Application. The MIT Press, London, 1999.

Sugiyanto. Zukhronah, E. dan Setianingrum, M. 2018. The Detection of Financial Crisis Using Combination of Volatility and Markov Switching Models Based on Real Output, Domestic Credit per GDP, and ICI indicators. Journal of Physics: Conference Series Vol. 1025. No. 012115

Tsay, R.S. 2002. Analysis of Financial Time Series. Canada: John Wiley and Sons Inc.

Muhammad, M.2014. Kointegrasi dan Estimasi ECM pada Data Time Series. Jurnal Konvergensi Vol 4 No 1.

Rosadi, D. 2010. Analisis Ekonometrika \& Runtun Waktu Terapan dengan R. Yogyakarta: Andi Yogyakarta.

Wahyudi, Y.2013. Pendekatan Early Warning Signals untuk Krisis Mata Uang Indonesia. Fakultas Ekonomi dan Bisnis: Universitas Kristen Satya Wacana. 